\title{
Physicians' Attitudes Towards Treating Patients in the Context of COVID-19 Pandemic in Pakistan
}

Maheen Ayub ${ }^{1}$, Daneyal Arshad ${ }^{1}$, Naheed Maqbool ${ }^{1}$, Mahnoor Zahid ${ }^{1}$, Rabia S. Malik ${ }^{1}$, Zuhair Ali Rizvi ${ }^{2}$ , Usman Arshad ${ }^{3}$, Saleem Ullah Khan ${ }^{4}$

1. Internal Medicine, Rawalpindi Medical University, Rawalpindi, PAK 2. Anesthesiology, Shifa International Hospital, Islamabad, PAK 3. Community Health Sciences, Ziauddin University, Karachi, PAK 4. Pediatric Surgery, Children's Hospital and Institute of Child Health, Lahore, PAK

Corresponding author: Daneyal Arshad, daneyal1997@gmail.com

\section{Abstract \\ Background and objectives}

Severe acute respiratory syndrome coronavirus 2 (SARS-CoV-2) has been the cause of a worldwide outbreak of respiratory illness, which has been declared as coronavirus disease 2019 (COVID-19) pandemic by the World Health Organization (WHO). The outbreak has posed a huge challenge to countries around the world and has resulted in a global lockdown. The pandemic has especially overburdened the healthcare sector, resulting in a shortage of personnel and equipment. Along with many other manifestations, it has resulted in stress and anxiety for the physicians as well. Furthermore, many healthcare workers have been reluctant in treating COVID-19 patients. This study aimed to explore the concerns of physicians in the context of the COVID-19 pandemic and to evaluate the reasons for their reluctance to treat the patients.

\section{Methodology}

This descriptive cross-sectional study included 235 physicians from seven hospitals of Pakistan who were actively working amid the COVID-19 pandemic. Data were collected from March 1, 2020, to May 30, 2020, using a structured online questionnaire. Participants were approached via non-probability convenient sampling. Two hundred and eight respondents were included in the data analysis. SPSS Statistics version 23.0 (IBM Corp., Armonk, NY) was used for data entry and analysis.

\section{Results}

A striking $83.7 \%$ ( $n=174$ ) of the respondents expressed their reluctance to treat patients with COVID-19. Concerns they raised included one or more of the following four reasons; lack of proper personal protective equipment (PPE), fear of self-infection, excessive workload, and fear of transmitting the infection to their family members. Of note, $92 \%$ ( $n=161$ ) of the respondents reported a lack of PPE while $74.1 \%(n=129)$ reported fear of transmitting the infection to their family members as reasons for their reluctance. The vast majority of the participants reported the need for psychological training to treat the patients' anxiety $(95.2 \%, n=198)$. Many participants were afraid that their own anxiety might be affecting the quality of care patients were receiving $(67.3 \%, \mathrm{n}=140)$. Hence, most of the participants reported that psychological counseling should be provided (93.3\%, $\mathrm{n}=194)$. Participants with family members older than 60 years were found to be reluctant to treat patients due to the risk of transmitting the infection to them $(69.7 \%, \mathrm{n}=145$, $\mathrm{p}=0.001)$. Therefore, a major proportion of the participants $(96.2 \%, \mathrm{n}=200)$ felt that the hospitals should provide a place for them to rest and temporarily isolate themselves to avoid coming into contact with their family members.

\section{Conclusions}

We conclude that a major proportion of physicians is reluctant to treat their patients due to multiple factors. The grave situation of the pandemic has taken a toll on their mental health, which could be affecting the quality of care that the patients receive. Their concerns should be addressed to not only provide them with support and improve their working environment but also to ensure that they are fully equipped to provide state-of-the-art care to the patients in these grave times.

Categories: Psychiatry, Infectious Disease, Public Health

Keywords: covid-19, personal protective equipment, reluctance, public health care, mental health

\section{Introduction}

The World Health Organization's (WHO) country office in China received the first notification about a pneumonia of unknown origin in Wuhan, Hubei province on December 31, 2019. On January 2, 2020, 41 patients admitted to a hospital in Wuhan, China, were found positive for the novel coronavirus, later termed as severe acute respiratory syndrome coronavirus-2 (SARS-CoV-2). The Director-General of WHO declared 
the novel coronavirus outbreak a public health emergency of international concern on January 30, 2020. On February 26, 2020, Pakistan confirmed its first two cases of coronavirus in Karachi and Islamabad. By March 13, there were 737 deaths and 34,336 cases reported in Pakistan [1].

The disease caused by SARS-CoV-2 was termed coronavirus disease 2019 (COVID-19) [2]. It is an infectious disease manifesting as a respiratory illness that can range from common cold to severe pneumonia and can be fatal in some cases. It is transmitted from one person to another through respiratory droplets.

Transmission by indirect contact with surfaces has also been reported [3]. The symptoms can range from mild fever, cough, and shortness of breath to severe symptoms like pneumonia and kidney failure, which can lead to fatal outcomes [2]. Frequent washing of hands, wearing a mask, and social distancing have proven to limit the risk of exposure.

With the emergence of this pandemic, the number of patients presenting to the hospitals has drastically increased. The workload for healthcare workers dealing with COVID-19 patients has also increased dramatically, as confirmed by a study conducted in Iran [4]. In addition to being a huge challenge to the physical well-being of the society, the COVID-19 pandemic is seriously affecting the mental health of not only the general public but also the healthcare providers. The psychological toll that managing the patients with COVID-19 has on the mental health of physicians and nurses has been unprecedented. The care-givers have to often decide on the allocation of the limited resources to the patients that need it the most. A British Broadcasting Corporation (BBC) article has rightly described the situation as "the young doctors being asked to play god" [5]. Furthermore, many healthcare workers are reluctant to come to hospitals and treat COVID19 patients, as demonstrated by a report by the Columbia Broadcasting System (CBS) News [6]. A significant number of healthcare workers have themselves contracted the disease and many have also died due to the disease.

The psychological impacts have been the result of overwhelming work as well as an inherent panic. They can impair the quality of care provided to the patients which, in this chaotic situation, would be disastrous. Therefore, we aimed to report the concerns of physicians amid the pandemic and to assess the reasons for their reluctance to treat COVID-19 patients. We sought to provide a comprehensive overview, in order to highlight the possible ways to ameliorate the concerns of physicians in the context of the ongoing pandemic.

\section{Materials And Methods}

This cross-sectional observational study was conducted among physicians from seven hospitals of Punjab, which included Holy Family Hospital, Benazir Bhutto Hospital, District Headquarters Hospital, Maroof International Hospital, Shifa International Hospital, Nishtar Hospital, and Basic Health Unit of District Kasur. A total of 235 physicians, who were actively working in these hospitals during the pandemic, were approached via convenient sampling. Data were collected using a structured questionnaire from March 1, 2020, to May 30, 2020. Doctors who were not involved in screening, diagnosing, and managing COVID-19 patients were excluded from the study.

After getting approval from the relevant ethical review board, the participants were approached and explained the purpose and importance of this study. Consent was obtained and confidentiality was ensured throughout the study. The participants were also informed that they could opt out of the study at any time.

Data were analyzed using SPSS Statistics version 23.0 (IBM Corp., Armonk, NY). Fourteen participants had missing data and were excluded from the analysis. Six participants withdrew consent. Data analysis included 208 participants with complete data. Descriptive statistics were obtained. Means and standard deviations were reported for normally distributed variables. Independent samples t-test and chi-square tests were used wherever applicable.

\section{Results}

Data analysis included 208 respondents, among which $33.7 \%(n=70)$ were males and $66.3 \%(n=138)$ were females. The mean age of the respondents was $25.44 \pm 2.34$ years. The majority of the participants consisted of house officers $(66.8 \%, n=139)$ and medical officers $(19.2 \%, n=40)$ (Table 1$)$. Of note, 68\% ( $n=143)$ of the participants had no prior experience of working during an epidemic. Only $10.6 \%(n=22)$ of the respondents reported undergoing special training to deal with and treat COVID-19 patients. 


\section{Cureus}

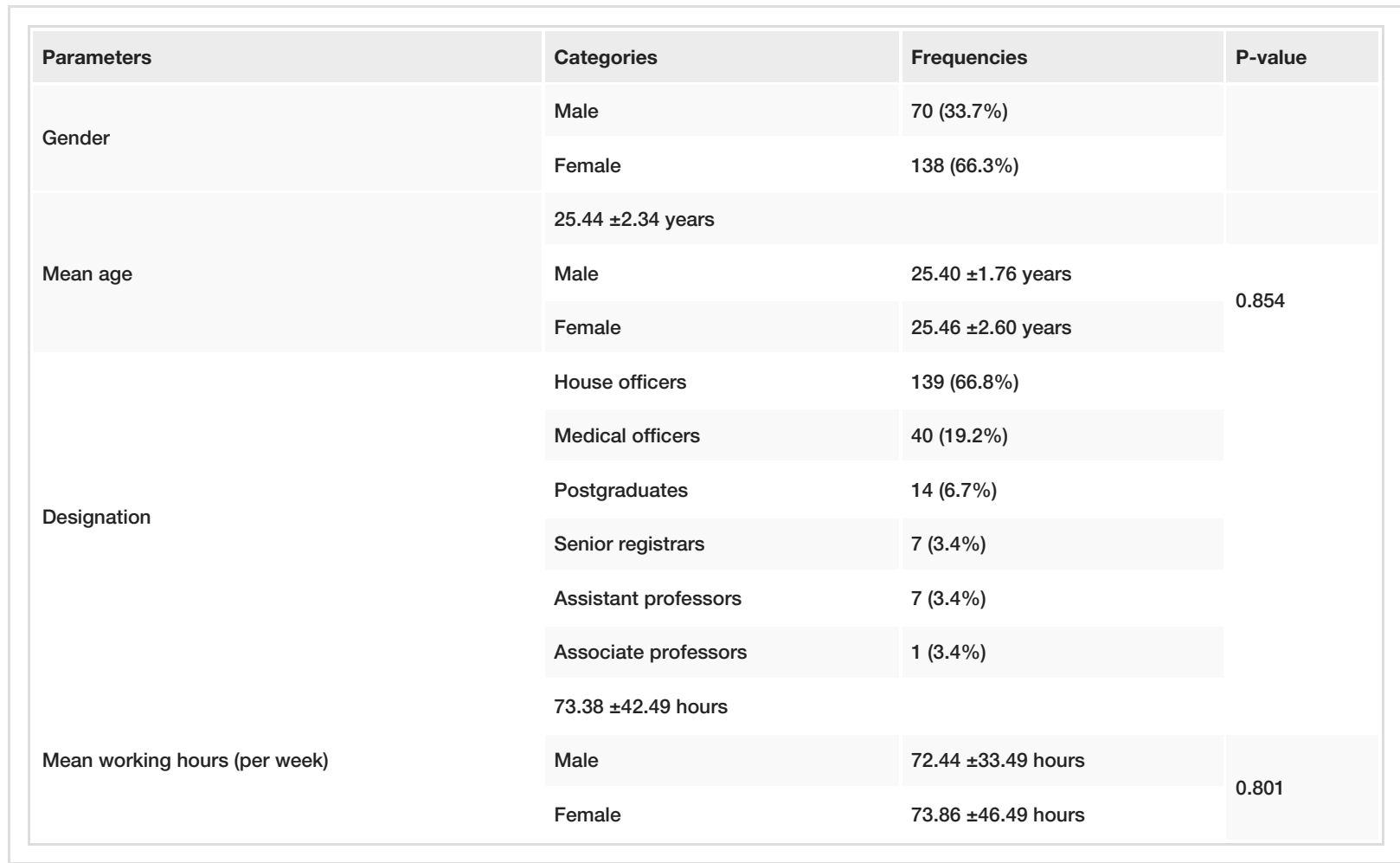

TABLE 1: Demographic characteristics of the participants

A staggering $83.7 \%$ ( $\mathrm{n}=174$ ) of the participants expressed their reluctance to treat COVID-19 patients. Reasons for their reluctance were one or more of the following four hazardous factors: lack of proper personal protective equipment (PPE), fear of self-infection, excessive work burden, and fear of transmitting Infection to their family members; $92 \%(n=161)$ reported a lack of proper PPE while $74.1 \%(n=129)$ respondents expressed their fear of transmitting the infection to their families and loved ones as reasons for their reluctance.

Among the participants, $17 \%(\mathrm{n}=36)$ reported simultaneous exposure to trauma and stressful conditions, and the majority of these participants were house officers $(58.33 \%, n=21, p=0.26) ; 34 \%(n=71)$ of the participants reported that there was no trend of shift rotation at their hospitals, and $22 \%(n=46)$ of the respondents reported living in unfavorable living conditions in the doctor's rooms at the hospitals.

Significantly, 76\% ( $\mathrm{n}=160)$ of the participants reported that they were overwhelmed with their workload $(\mathrm{p}<0.001) ; 88 \%$ of respondents $(\mathrm{n}=185)$ reported that they did not know how to deal with patients who were not willing to be quarantined or were resisting to take proper protective measures. And $95 \%$ of respondents $(n=198)$ felt that there should be psychological training to deal with patients who were anxious or panicking. Nearly all participants $(99.03 \%, \mathrm{n}=206)$ reported that staff should be available to deal with uncooperative patients.

Remarkably, $92 \%$ of respondents ( $n=192)$ reported that they faced a shortage of masks and other protective measures. All participants felt the need for training on how to use protective equipment; $78 \%$ of the respondents ( $\mathrm{n}=164)$ had people older than 60 years in their households. Of note, $96 \%$ of the participants $(n=200)$ expressed that the hospital should provide a place where the staff could rest and temporarily isolate themselves from their family to avoid exposing themselves to and infecting their families. Table 2 provides a comprehensive overview of all the questions posed to the participants and their responses.

\section{Questions}

1. Have you ever worked in an epidemic before? 


\section{Cureus}

3. Did you have training on how to approach and deal with these patients?

Yes $22 \quad 10.6 \%$

4. Do you know how to deal with patients unwilling to be quarantined or to take protective measures?

No $186 \quad 89.4 \%$

Yes $23 \quad 11.1 \%$

No $18588.9 \%$

5. Do you face a shortage of masks and other protective equipment?

Yes $192 \quad 92.3 \%$

No $\quad 16 \quad 7.7 \%$

Yes $164 \quad 78.8 \%$

6. Are there people older than 60 years at your home that you're in contact with?

No $\quad 44 \quad 21.2 \%$

7. Do you think there should be training on psychological skills to deal with patients' anxiety, panic, and other emotional problems?

Yes $198 \quad 95.2 \%$

No $\quad 10 \quad 4.8 \%$

8. Do you think the hospital should provide a place for rest where staff could temporarily isolate themselves from their family?

Yes $200 \quad 96.2 \%$

No $8 \quad 3.8 \%$

Yes $206 \quad 99.0 \%$

9. Do you think staff should be available to deal with uncooperative patients?

10. Do you think there should be proper training regarding how to use protective equipment?

11. Do you think maintaining the mental health of staff is essential to deal with patients?

12. Do you think stress-relieving activities should be arranged for staff?

13. Do you think psychological counselors should regularly visit to counsel staff at work and provide support if needed?

14. Do you think your anxiety is affecting the quality of care patients should receive?

15. Do you think working under these conditions would lead to residual long-term effects on your mental health?

16. Do you feel overwhelmed and overextended with the workload?

17. Do you have a history of physical and/or psychological disorders?

18. Did you have any simultaneous exposure to other traumas or recent stressful situations?

19. Do you experience unfavorable living conditions at the healthcare facility?

20. Do you have a system of work rotation at your hospital?

21. Do you take satisfactory precautionary measures?

22. Do you have access to free counseling and therapy?

No $2 \quad 1.0 \%$

Yes $208 \quad 100.0 \%$

No $\quad 0 \quad 0.0 \%$

Yes $208 \quad 100.0 \%$

No $0 \quad 0.0 \%$

Yes $202 \quad 97.1 \%$

No $6 \quad 2.9 \%$

Yes $194 \quad 93.3 \%$

No $14 \quad 6.7 \%$

Yes $140 \quad 67.3 \%$

No $\quad 68 \quad 32.7 \%$

Yes $145 \quad 69.7 \%$

No $63 \quad 30.3 \%$

Yes $160 \quad 76.9 \%$

No $48 \quad 23.1 \%$

Yes $26 \quad 12.5 \%$

No $182 \quad 87.5 \%$

Yes $36 \quad 17.3 \%$

No $172 \quad 82.7 \%$

Yes $\quad 46 \quad 22.1 \%$

No $162 \quad 77.9 \%$

Yes $137 \quad 65.9 \%$

No $\quad 71 \quad 34.1 \%$

Yes $124 \quad 59.6 \%$

No $84 \quad 40.4 \%$

Yes $43 \quad 20.7 \%$

No $\quad 165 \quad 79.3 \%$ 


\section{Cureus}

23. Do you do any physical and relaxation exercises to relieve your stress?

Yes $\quad 35 \quad 16.8 \%$

Diche

No $\quad 173 \quad 83.2 \%$

24. Do you get enough rest and sleep?

Yes $\quad 86 \quad 41.3 \%$

No $\quad 122 \quad 58.7 \%$

Yes $\quad 77 \quad 37.0 \%$

25. Do you eat a regular balanced meal?

No $\quad 131 \quad 63.0 \%$

Yes $12258.7 \%$

26. Do you participate in family and social activities?

No $86 \quad 41.3 \%$

Yes $16192.5 \%$ a

27. Is lack of PPE one of the reasons for your reluctance?

No $13 \quad 7.5 \%$ a

Yes $73 \quad 42.0 \%^{a}$

28. Is the fear of self-infection one of the reasons for your reluctance?

No $10158.0 \%^{a}$

Yes $12974.1 \%^{\mathrm{a}}$

29. Is the fear of transmitting the infection to family members one of the reasons for your reluctance?

No $45 \quad 25.9 \%$ a

Yes $13 \quad 7.5 \%$ a

30. Is too much workload one of the reasons for your reluctance?

No $16192.5 \%$ a

\section{TABLE 2: Questionnaire responses}

aPercentage of doctors who were reluctant $(n=174)$

PPE: personal protective equipment

\section{Mental health concerns}

All of the respondents $(n=208)$ felt that the mental health of the staff was equally important to control the situation and to deal with patients. Of note, $67 \%$ of respondents $(n=140)$ thought that their anxiety is affecting the quality of care patients should receive; $97 \%(n=202)$ of respondents felt that stress-reducing activities should be arranged for staff in this regard, and $93 \%$ ( $n=194)$ of the respondents reported that psychological counselors should be available to provide regular counseling and emotional support. Only $20.7 \%(n=43)$ of the physicians had access to free counseling.

Of the participants, $69 \%(n=145)$ felt that working in these circumstances would lead to some residual longterm effects on their mental health. And $76 \%(\mathrm{n}=160)$ of respondents felt overwhelmed and overextended with the workload; $17 \%(\mathrm{n}=36)$ of the respondents had simultaneous exposure to traumas and other stressful situations, and $22 \%$ of the participants $(n=46)$ experienced unfavorable living conditions. Also, $65 \%$ of respondents ( $\mathrm{n}=137)$ reported that they had a system of work rotation in their hospital.

Of note, $59 \%(n=124)$ of respondents stated that they took satisfactory precautionary measures; $16 \%(n=35)$ of respondents did physical and relaxation exercises to relieve stress. Only $37 \%$ of respondents $(n=77)$ were able to eat a regular balanced meal. More than half of the respondents $(58.7 \%, \mathrm{n}=122)$ participated in family and social events regularly, and $58 \%$ of the participants $(n=122)$ had not been able to get enough rest and were sleep-deprived.

\section{Factors associated with the reluctance to treat COVID-19 patients}

All 46 of the participants with unfavorable living conditions were reluctant to treat COVID-19 patients $(\mathrm{p}<0.001)$. Of the 71 participants who did not have a system of work rotation at their hospital, 61 were reluctant to treat COVID-19 patients $(\mathrm{p}=0.010)$.

Notably, $88 \%(\mathrm{n}=145)$ of the 164 participants having elderly relatives at home were reluctant to treat COVID19 patients $(\mathrm{p}=0.001)$. Among participants with no prior experience of working in an epidemic, $83.21 \%$ $(\mathrm{n}=119)$ were reluctant to treat COVID-19 patients $(\mathrm{p}=0.487) ; 81 \%(\mathrm{n}=152)$ of the participants who received 
no prior training to deal with COVID-19 patients were reluctant to treat them $(\mathrm{p}=0.016)$. Of the 192 respondents who reported unavailability of masks and PPE, $86.45 \%(n=166)$ were reluctant to treat COVID19 patients $(\mathrm{p}=0.01)$ (Table 3$)$.

\begin{tabular}{|c|c|c|c|c|}
\hline & & \multicolumn{2}{|c|}{$\begin{array}{l}\text { Are you reluctant to treat COVID-19 } \\
\text { patients? }\end{array}$} & \multirow{2}{*}{$\begin{array}{l}\text { P- } \\
\text { Value }\end{array}$} \\
\hline & & Yes & No & \\
\hline \multirow{2}{*}{ 1. Are there people older than 60 years in your home that you are in contact with? } & Yes & 145 & 19 & \multirow{2}{*}{$0.001^{\star *}$} \\
\hline & No & 29 & 15 & \\
\hline \multirow{2}{*}{ 2. Did you face a shortage of masks and other protective equipment? } & Yes & 166 & 26 & \multirow{2}{*}{$0.01^{*}$} \\
\hline & No & 8 & 8 & \\
\hline \multirow{2}{*}{ 3. Do you experience an unfavorable living condition at the healthcare facility? } & Yes & 46 & 0 & \multirow{2}{*}{$0.000^{\star \star}$} \\
\hline & No & 128 & 34 & \\
\hline \multirow{2}{*}{$\begin{array}{l}\text { 4. Have you undergone a simultaneous exposure to other traumas or recent stressful } \\
\text { situations? }\end{array}$} & Yes & 36 & 0 & \multirow{2}{*}{$0.001^{\star \star}$} \\
\hline & No & 138 & 34 & \\
\hline \multirow{2}{*}{ 5. Do you think your anxiety is affecting the quality of care patients should receive? } & Yes & 122 & 18 & \multirow{2}{*}{$0.042^{*}$} \\
\hline & No & 52 & 16 & \\
\hline \multirow{2}{*}{$\begin{array}{l}\text { 6. Do you know how to deal with patients unwilling to be quarantined or take } \\
\text { protective measures? }\end{array}$} & Yes & 16 & 7 & \multirow{2}{*}{0.057} \\
\hline & No & 158 & 27 & \\
\hline \multirow{2}{*}{ 7. Did you have training on how to approach and deal with these patients? } & Yes & 22 & 0 & \multirow{2}{*}{$0.016^{\star}$} \\
\hline & No & 152 & 34 & \\
\hline \multicolumn{5}{|c|}{ TABLE 3: Associations of questionnaire responses with reluctance to treat COVID-19 patients } \\
\hline \multicolumn{5}{|l|}{ COVID-19: coronavirus disease 2019} \\
\hline
\end{tabular}

\section{Discussion}

The COVID-19 pandemic has claimed the lives of not only the general public but also many healthcare workers and is continuing to do so. The deaths of many healthcare workers, including doctors, have occurred due to the coronavirus pandemic [7-9]. The toll on the mental health of healthcare workers has been equally severe. Doctors all around the world have been facing the difficult task of "rationing" medical supplies and facilities. They have had to decide which of the patients should receive treatment on a priority basis. The complexity of this situation was rightly summarized by a BBC article titled "the young doctors being asked to play god" [5]. This adverse situation has led to heart-breaking scenarios and even the suicide of a doctor who was actively involved in treating patients with COVID-19 [10].

The sheer psychological impact of this grave situation is severe enough to leave a lasting mark on a doctor's mental health. Apart from this, it has also given rise to multiple concerns among physicians treating COVID19 patients, many of whom are often reluctantly engaged in treating COVID-19 patients. It was observed in our study that most of the concerns arose because of insufficient protective measures the healthcare workers were provided with. Excessive working hours, the overwhelming nature of the work, and fear of selfinfection were also the reasons behind these concerns. We have observed in our study that many of our physicians expressed their wish to have psychological counseling and training.

Notably, 83\% of our 208 participants expressed their reluctance to treat COVID-19 patients. The reasons included lack of protective gear, fear of self-infection and infecting family members, and excessive workload. Many of the doctors faced unfavorable living conditions. They also had to deal with uncooperative patients. A large number of physicians felt that their mental health was also affecting the level of care the patients should receive.

The results of our study in Pakistani healthcare settings are similar to those observed globally. A study 
conducted among healthcare workers in China also showed that a considerable proportion of healthcare workers reported experiencing symptoms of depression, anxiety, insomnia, and psychological distress [11]. Another study conducted in Hong Kong reported a high prevalence of distress among healthcare workers and linked it to three factors: vulnerability, fear for self-health, and spread of the virus [12].

Healthcare workers around the world have also expressed their concerns about unknowingly transmitting the infection to family members, especially those who are elderly or those with chronic medical conditions [13]. Another qualitative study assessing the challenges of working in the scenario of an infectious evolutionary and extra workload faced by healthcare workers reported that healthcare workers felt they were "powerless to help their patients". They also feared getting infected themselves as well as infecting further people, including family and patients. Their relationships were also affected. They also found working with protective gear and heavy workload exhausting [14].

Our study was an attempt to assess the mental burden this pandemic has put on the healthcare workers. In light of our findings, we recommend that adequate psychological help and counseling should be provided to the healthcare workers. Being the front-line warriors against the pandemic, we cannot afford to lose them at the hands of this contagious disease, and nor should we let them deteriorate psychologically. Therefore, the provision of an appropriate amount of PPE should be ensured. The working schedule should allow doctors to take breaks and should ensure that they are not overworked. Steps should also be taken by the government and healthcare officials to ensure that such problems are better dealt with in case of a reoccurrence.

\section{Conclusions}

COVID-19 pandemic has wreaked unprecedented havoc on our healthcare system as well as healthcare personnel. Many of the physicians have expressed fear and reluctance to treat patients due to a lack of PPE, fear of self-infection, and fear of transmitting the infection to family members. In addition, they also face drastic circumstances that have taken a toll on their mental health, which in turn can affect the quality of care that the patients receive. Therefore, it has been suggested that adequate psychological counseling should be made available to healthcare workers. Steps need to be taken to provide them with all the support they require in order to ensure a healthy working environment as well as to make sure that the patients receive state-of-the-art quality of care.

\section{Additional Information}

\section{Disclosures}

Human subjects: All authors have confirmed that this study did not involve human participants or tissue. Animal subjects: All authors have confirmed that this study did not involve animal subjects or tissue. Conflicts of interest: In compliance with the ICMJE uniform disclosure form, all authors declare the following: Payment/services info: All authors have declared that no financial support was received from any organization for the submitted work. Financial relationships: All authors have declared that they have no financial relationships at present or within the previous three years with any organizations that might have an interest in the submitted work. Other relationships: All authors have declared that there are no other relationships or activities that could appear to have influenced the submitted work.

\section{References}

1. Confirmed coronavirus cases surge to 34,336 in Pakistan . (2020). Accessed: July 7, 2020: https://nation.com.pk/13-May-2020/confirmed-coronavirus-cases-surge-to-34-336-in-pakistan.

2. Coronavirus disease 2019 (COVID-19) - symptoms and causes - Mayo Clinic . (2020). Accessed: July 10, 2020: https://www.mayoclinic.org/diseases-conditions/coronavirus/symptoms-causes/syc-20479963.

3. Modes of transmission of virus causing COVID-19: implications for IPC precaution recommendations . (2020). Accessed: July 9, 2020: https://www.who.int/news-room/commentaries/detail/modes-oftransmission-of-virus-causing-covid-19-implications-for-ip....

4. Shoja E, Aghamohammadi V, Bazyar H, et al.: Covid-19 effects on the workload and mental health of Iranian healthcare workers [PREPRINT]. Res Square. 2020, 10.21203/rs.3.rs-27866/v1

5. Coronavirus: the young doctors being asked to play God . (2020). Accessed: July 10, 2020: https://www.bbc.com/news/world-us-canada-52137160.

6. Doctors and nurses "scared to come to work" to treat coronavirus patients because of supply shortages . (2020). Accessed: July 10, 2020: https://www.cbsnews.com/news/coronavirus-doctors-nurses-medicalsupply-shortages/.

7. Ing EB, Xu QA, Salimi A, Torun N: Physician deaths from corona virus (COVID-19) disease . Occup Med (Lond). 2020, 70:370-374. 10.1093/occmed/kqaa088

8. Pakistan has lost 42 doctors among 58 healthcare providers to COVID-19 . (2020). Accessed: July 10, 2020: https://www.thenews.com.pk/print/680655-pakistan-has-lost-42-doctors-among-58-healthcare-providersto-covid-19.

9. Russia: almost 500 doctors die from COVID-19. (2020). Accessed: July 10, 2020: https://www.aa.com.tr/en/europe/russia-almost-500-doctors-die-from-covid-19/1881745.

10. NYC emergency room physician who treated coronavirus patients dies by suicide . (2020). Accessed: July 10, 2020: https://www.npr.org/sections/coronavirus-live-updates/2020/04/28/847305408/nyc-emergency-roomphysician-who-treated-c.... 


\section{Cureus}

11. Lai J, Ma S, Wang Y, et al.: Factors associated with mental health outcomes among health care workers exposed to coronavirus disease 2019. JAMA Netw Open. 2020, 3:e203976.

10.1001/jamanetworkopen.2020.3976

12. Wong TW, Yau JK, Chan CL, et al.: The psychological impact of severe acute respiratory syndrome outbreak on healthcare workers in emergency departments and how they cope. Eur J Emerg Med. 2005, 12:13-18. 10.1097/00063110-200502000-00005

13. Adams JG, Walls RM: Supporting the health care workforce during the COVID-19 global epidemic . JAMA. 2020, 323:1439-1440. 10.1001/jama.2020.3972

14. Liu Q, Luo D, Haase JE, et al.: The experiences of health-care providers during the COVID-19 crisis in China: a qualitative study. Lancet Glob Health. 2020, 8:e790-e798. 10.1016/S2214-109X(20)30204-7 